\title{
Free school meals and children's social and nutritional status in Trinidad and Tobago
}

\author{
MC Gulliford ${ }^{1, *}$, D Mahabir ${ }^{2}$, B Rocke ${ }^{2}$, S Chinn ${ }^{1}$ and RJ Rona ${ }^{1}$ \\ 'Department of Public Health Sciences, King's College London, Capital House, 42 Weston Street, London SE 1 3QD, \\ UK: ${ }^{2}$ Nutrition and Metabolism Division, Ministry of Health, Trinidad and Tobago
}

Submitted 24 August 2001: Accepted 18 January 2002

\begin{abstract}
Objective: To evaluate the provision of free school meals in Trinidad and Tobago in relation to children's social and nutritional status.

Design and methods: Cross-sectional survey of a nationally representative sample of 66 government schools, including children in the admissions classes (aged 4 to 7 years) and classes for 'rising nines' (aged 7-10 years). Data included questionnaire details of free school meals and children's social background, and measurements of children's heights, weights and skinfold thicknesses.

Results: Of 6731 eligible children, data were analysed for 5688 (85\%). There were 2386 (42\%) children receiving free meals provided at school. At different schools the proportion of all children receiving free meals ranged from $20 \%$ to $100 \%, P<0.001$. Receipt of free meals was associated with larger family size (one child, 32\% received free meals; $\geq 6$ children, 63\%), lower paternal educational attainment (primary, 52\% free; university, 30\%), father's employment (employed, 39\% free meals; unemployed $>12$ months, 59\%) as well as maternal education and employment and household amenities. After adjusting for age, sex and ethnic group, children who received free meals were shorter (mean difference in height standard deviation score (SDS) -0.12 , $95 \%$ confidence interval (CI) -0.17 to -0.06 ), lighter (body mass index SDS -0.21 , -0.28 to -0.14 ) and thinner (subscapular skinfold SDS $-0.13,-0.18$ to -0.09 ).

Conclusions: Free school meals were widely available, with some targeting of provision to children with less favourable social and nutritional status. Greater universality would reduce inequity, but more stringent targeting and reduction of school-level variation would increase efficiency.
\end{abstract}

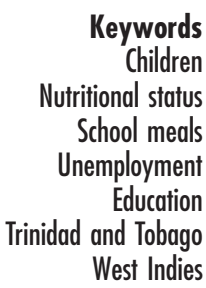

eywords

anal status

School meals

Education

West Indies
In the Caribbean, there has been a long-standing concern with the nutritional status of children. Sinha reviewed evidence from different English-speaking countries and reported that nutritional conditions had greatly improved over time ${ }^{1}$. Nevertheless, concerns continue to be expressed about undernutrition in socially disadvantaged sections of the population, particularly during periods of economic recession ${ }^{2}$. In response to these concerns, the government in Trinidad and Tobago has extended the coverage of free school meals in recent years. The programme covers all government and governmentassisted (denominational) schools but not private schools. In total about 85000 students receive meals in primary, secondary and pre-school classes. The programme is evolving and the ultimate intention is to reach all students. Meals provided by the school nutrition programme are free of charge, and are supplied daily. In primary schools, teachers select children for free meals using guidelines provided by the Ministry of Education. Selection is based on the employment status of the parents, the number of children in the family, and whether the child has a specific medical condition. In this report we aimed to evaluate the extent of provision of free school meals to different groups of children in relation to their social and nutritional status. The data were collected through a survey of a nationally representative sample of government schools carried out by the Nutrition Division of the Ministry of Health during 1999.

\section{Methods}

\section{Subjects}

The methods and main results of the study have been reported in detail elsewhere ${ }^{3}$. There are 468 government primary schools in Trinidad and Tobago, 433 in Trinidad and 35 in Tobago. The sample of 66 schools was drawn by stratifying the country into health administrative areas and randomly selecting schools with probability proportional to size. The sample of schools was drawn by the Central Statistical Office for an earlier survey carried out in 1989. 
The same sample was used for this survey because the geographical distribution of children in that survey corresponded closely to the distribution observed in the 1990 census. Fieldwork was carried out in the first six months of 1999. Within each school we measured all children in the first-year classes and in the classes for children aged 8 to 9 years.

\section{Measurements}

Measurements were made of children's heights, weights, and triceps and subscapular skinfold thicknesses. Height was measured on a Holtain stadiometer using the method described by Cameron ${ }^{4}$. Height was measured to the last $0.1 \mathrm{~cm}$ and $0.05 \mathrm{~cm}$ was added to correct the bias. Children were weighed in underpants with weight recorded to the last complete $100 \mathrm{~g}$ using electronic digital scales. Triceps skinfold thickness was measured as recommended by Tanner and Whitehouse ${ }^{5}$ but with the measuring point marked instead with the arm hanging straight and not bent. Fieldwork was carried out by the nutritionists and food demonstrators from the Nutrition Division of the Ministry of Health. Staff were trained in measurement techniques before the start of the study.

\section{Questionnaires}

The parents of each child were asked to complete a questionnaire. Where necessary the questionnaire was interview-administered by a class teacher or a fieldworker.

The questionnaire included questions concerning whether the child usually ate 'breakfast', 'lunch' or any 'other food' (e.g. snacks) at school and, for each item, whether the food was provided free of charge. For analysis we combined responses to these items in order to determine whether each child received any free food at school or not. All meals provided by the government School Nutrition Programme are provided free of charge. Other meals would have been either brought to school or purchased from vendors near to the school. Children receiving no food at school were presumed to go home for lunch but we did not collect this specific information, nor did we collect information about the children receiving drink but not food at school.

The child's ethnic group was classified into the categories 'African', 'Indian', 'White', 'Chinese', 'Mixed', 'Other' or 'Not known', based on parental reports. This represents a shortened form of the categorisation used in the national census ${ }^{6}$. For analysis the categories were further reduced to 'Afro-Trinidadian', 'Indo-Trinidadian', 'Mixed' and 'Other and Not known'. The number of children in the family was included in analyses as a categorical variable. The questionnaire also included items concerning the educational attainment and employment status of the child's parents, the type of water supply available in the home and the number of persons per room as an index of overcrowding. For analysis, these variables were reduced to the categories shown in the tables.

\section{Analysis}

A standard deviation score (SDS) was calculated for measurements of height, weight, body mass index (BMI) and skinfold thicknesses. The SDS is given by the difference between the child's measurement and the mean for a child of the same age and gender from a reference population divided by the standard deviation for that age and sex in the reference population. Data from British children were used for reference. The height and weight SDSs $^{7}$ and BMI SDS $^{8}$ were calculated from the British 1990 growth references as recommended. Data for white children from the 1990 survey of the National Study of Health and Growth (NSHG) constituted the majority of the data for ages 5 to 11 years, and data from other surveys were adjusted to that of the NSHG English data ${ }^{8}$. No concurrent UK reference curves for skinfold thickness were produced because of the lack of data from studies other than the NSHG. SDSs have therefore been calculated directly from NSHG 1990 data for English white children. Reference curves for triceps and subscapular skinfold thickness were obtained using the method of Cole? ${ }^{9}$ By definition, each SDS had normal distribution mean of 0.0 and standard deviation of 1.0 for the English white 1990 population. In boys, one weight SDS is equivalent to about $1.9 \mathrm{~kg}$ at 5 years and $4.5 \mathrm{~kg}$ at 11 years. Eight outlying items of data were excluded because they appeared impossible (greater than 10 SDS or less than -10 SDS). The age distribution of the sample was clearly bimodal with a trough at 7 years. Children were therefore divided into two age groups - less than 7 years and 7 years or more - in order to examine the hypotheses in relation to age. School class ('admissions' or 'rising nines') was not entered on to computer, but would generally be consistent with age group.

There was appreciable school-level variation, so random effects logistic regression models were fitted using the 'xtlogit' command in Stata ${ }^{10}$. Random effects regression models (with school as the random effect) were used to estimate associations between height, body mass index or subscapular skinfold thickness and explanatory variables $^{10}$.

\section{Results}

There were 6731 eligible subjects in the sample. Measurements were obtained for 6405 (95\%) children, while both questionnaires and measurements were obtained for 5688 (85\%). After adjusting for age group, sex and observer-assessed ethnicity, there was only weak evidence that children who provided measurements but not questionnaire responses were slightly shorter (mean difference in height SDS -0.06, 95\% confidence interval 
Table 1 Proportion of children having meals at school and whether they were free of charge. Figures are frequencies (\% of column total)

\begin{tabular}{|c|c|c|c|c|c|c|}
\hline & \multicolumn{2}{|c|}{ All children (5688) } & \multicolumn{2}{|c|}{$<7$ years $(2608)$} & \multicolumn{2}{|c|}{$\geq 7$ years $(3080)$} \\
\hline & Received & Free & Received & Free & Received & Free \\
\hline Breakfast & $287(5)$ & 179 (3) & $119(5)$ & $71(3)$ & $168(5)$ & $108(4)$ \\
\hline Lunch & $3721(65)$ & $2146(38)$ & $1672(64)$ & $886(34)$ & 2049 (67) & $1260(41)$ \\
\hline Other food & 1294 (23) & $460(8)$ & 609 (23) & $224(9)$ & 685 (22) & $236(8)$ \\
\hline Any food & 4166 (73) & 2386 (42) & $1875(72)$ & $1011(39)$ & $2291(74)$ & 1375 (45) \\
\hline
\end{tabular}

(CI) -0.15 to $0.03, P=0.171$ ) and lighter (mean difference in BMI SDS $-0.06,-0.17$ to $0.05, P=0.279$ ) than children who provided both measurements and questionnaire responses. The remaining analyses were confined to the 5688 children who contributed both measurements and questionnaire responses. Parentally assigned ethnic group was used for analysis. In the younger age group, the median age (range) was 5.7 ( 4.4 to 6.9) years. In the older age group, the median age (range) was 8.6 (7.0 to 10.4 ) years.

Table 1 shows the proportion of children eating food in school, and whether they were receiving free meals. Overall, 4166 (73\%) children ate food at school, and lunch accounted for 3721 (89\%) meals in school. Free meals were received by 2386 (42\%) children, and lunch was provided in 2146 (90\%) cases. The level of provision was slightly higher in the older age group than in the younger. There was significant variation in the provision of free school meals among schools, with the proportion of all children receiving free meals ranging from $20 \%$ to $100 \%$ at different schools. The intra-class correlation coefficient for school-level variation (by analysis of variance, without adjustment for covariates) was 0.08 (95\% CI 0.05 to 0.11 ). This variation was partly explained on a geographical basis, with schools in Tobago (74\%) having a higher level of provision than those in Trinidad (41\%).

Table 2 shows the distribution of free meals according to children's social characteristics. Figures are frequencies (\% of row total) and odds ratios (95\% CI) from a logistic regression model adjusted for each of the variables shown. There was evidence that older, rather than younger children, and boys rather than girls more often received free meals in school, but the absolute differences between groups were small. There were no differences in the receipt of free meals in relation to ethnicity. There was a strong association between the number of children in the family and receipt of free meals, with a two-fold increase between one-child families and those with six or more children. Receipt of free meals was also associated with lower educational attainment in the father or mother, with long-term unemployment of the father, with absence of a pipe-borne water supply in the home, and with household overcrowding. There was only weak evidence for an association with maternal employment status. There was evidence of school-level variation $(P<0.001)$ even after allowing for variation in children's social characteristics between schools, and whether the school was in Tobago.

Table 3 shows the mean difference (95\% CI) for anthropometric indicators between those who received free meals and those who did not. In these analyses, which were adjusted for age group, sex and ethnic group, children who received free meals were slightly shorter, thinner and lighter than those who did not. Comparing children who ate food at school that was not free with children who did not eat at school, there were no differences in mean height SDS $(-0.02,95 \% \mathrm{CI}-0.09$ to $0.05)$, BMI SDS $(-0.02,-0.11$ to 0.07$)$, triceps skinfold thickness SDS $(0.01,-0.07$ to 0.08$)$ or subscapular skinfold thickness SDS $(0.01,-0.05$ to 0.07$)$.

\section{Discussion}

\section{Main findings}

A high proportion of primary school children in Trinidad and Tobago received free school meals. Receipt of free school meals was associated with the child being from a larger family, with lower educational attainment of either the mother or the father, with long-term unemployment of the father, and with fewer household amenities in terms of water supply and household overcrowding. Children who received school meals were slightly shorter, lighter and thinner than children who did not receive school meals. There was evidence of variation in provision among schools, even after allowing for differences in children's characteristics between schools. There also appeared to be different levels of provision of free meals in Trinidad as compared with Tobago.

\section{Limitations of the study}

Our study had several limitations. We studied a large nationally representative sample of children, and the overall response rate was good. However, there is a concern that non-responding children may represent a particularly vulnerable group, especially as we did not trace children who were not registered in school. However, the proportion of children not enrolled in school would be a very small minority in Trinidad and Tobago. As the survey had a broad perspective, we only included a few simple questions about the meals taken at school. Future studies might usefully evaluate the food 
Table 2 Proportion of children receiving free food in relation to social factors. Figures are frequencies (\% of row total) and odds ratios $(95 \% \mathrm{Cl})$ adjusted for each of the variables shown

\begin{tabular}{|c|c|c|c|}
\hline & & Free meals/total (\%) & Odds ratio $(95 \% \mathrm{Cl})$ \\
\hline \multirow[t]{2}{*}{ Age-group } & $<7$ years & 10112608 (39) & - \\
\hline & $\geq 7$ years & $13753080(45)$ & $1.18(1.05$ to 1.33$)$ \\
\hline \multirow{2}{*}{ Sex } & Male & 12102737 (44) & - \\
\hline & Female & $11762951(40)$ & 0.81 (0.71 to 0.91$)$ \\
\hline \multirow[t]{4}{*}{ Ethnic group } & Afro-Trinidadian & $8261934(43)$ & - \\
\hline & Indo-Trinidadian & $7271689(43)$ & $0.91(0.75$ to 1.11$)$ \\
\hline & Mixed & 7731794 (43) & 1.19 (1.03 to 1.38$)$ \\
\hline & Other and Not known & $60271(22)$ & 0.57 (0.38 to 0.84$)$ \\
\hline \multirow[t]{7}{*}{ Number of children in family } & 1 & $241760(32)$ & - \\
\hline & 2 & $5771661(35)$ & 1.09 (0.90 to 1.33$)$ \\
\hline & 3 & $5161204(43)$ & 1.27 (1.03 to 1.56$)$ \\
\hline & 4 & $396833(48)$ & $1.48(1.18$ to 1.85$)$ \\
\hline & 5 & $266456(58)$ & 2.01 (1.54 to 2.63 ) \\
\hline & $\geq 6$ & $328522(63)$ & 2.11 (1.61 to 2.75$)$ \\
\hline & Not known & $62252(25)$ & $0.79(0.53$ to 1.18$)$ \\
\hline \multirow[t]{5}{*}{ Mother's education } & Primary & $8311513(55)$ & - \\
\hline & Secondary & $10232587(40)$ & 0.80 (0.69 to 0.93$)$ \\
\hline & Technical & 3701056 (35) & 0.77 (0.64 to 0.93$)$ \\
\hline & University & $63224(28)$ & $0.73(0.51$ to 1.05$)$ \\
\hline & Not known & 99308 (32) & 0.81 (0.57 to 1.15$)$ \\
\hline \multirow[t]{5}{*}{ Father's education } & Primary & $9171751(52)$ & - \\
\hline & Secondary & $8402144(39)$ & $0.86(0.74$ to 1.00$)$ \\
\hline & Technical & 303932 (33) & $0.72(0.59$ to 0.87$)$ \\
\hline & University & $79265(30)$ & 0.78 (0.57 to 1.08$)$ \\
\hline & Not known & 247596 (41) & 0.99 (0.78 to 1.25$)$ \\
\hline \multirow[t]{3}{*}{ Mother's employment } & Housewife/not employed & 13622891 (47) & - \\
\hline & In paid employment & 7412071 (36) & $0.91(0.79$ to 1.04$)$ \\
\hline & Not known & $283726(39)$ & 0.98 (0.79 to 1.21$)$ \\
\hline \multirow[t]{4}{*}{ Father's employment } & Employed & 15653966 (39) & - \\
\hline & Unemployed & $234456(51)$ & $1.18(0.95$ to 1.45$)$ \\
\hline & Unemployed $>12$ months & $207352(59)$ & $1.58(1.24$ to 2.01$)$ \\
\hline & Not known & 380914 (42) & $1.24(1.02$ to 1.49$)$ \\
\hline \multirow[t]{3}{*}{ Water supply } & Piped supply in house & $12453457(36)$ & - \\
\hline & No piped supply in house & $10171842(55)$ & $1.58(1.38$ to 1.81$)$ \\
\hline & Not known & $124389(32)$ & 0.94 (0.71 to 1.26$)$ \\
\hline \multirow[t]{5}{*}{ Overcrowding (persons/room) } & $\leq 1.0$ & $4821529(32)$ & - \\
\hline & $>1.0$ to $\leq 1.5$ & $5301357(39)$ & 1.07 (0.91 to 1.27$)$ \\
\hline & $>1.5$ to $\leq 2.0$ & $6251321(47)$ & 1.31 (1.10 to 1.56$)$ \\
\hline & $>2.0$ & $6721176(57)$ & $1.46(1.21$ to 1.77$)$ \\
\hline & Not known & $77305(25)$ & 0.77 (0.54 to 1.10$)$ \\
\hline \multirow[t]{2}{*}{ Island } & Trinidad & $22845551(41)$ & - \\
\hline & Tobago & $10237(74)$ & $3.73(1.68$ to 8.30$)$ \\
\hline
\end{tabular}

intakes of children who do not receive meals through the school feeding programme, or who do not eat at school.

\section{Comparison with other work}

Meals are provided for children in school at reduced or no cost in many countries, with the intention of improving children's dietary intakes and ultimately their nutritional

Table 3 Mean difference $(95 \% \mathrm{Cl})$ in anthropometric measures between children receiving free meals and those not

\begin{tabular}{lcc}
\hline Measure & $\begin{array}{l}\text { Mean difference } \\
(95 \% \mathrm{Cl}) \text { SDS }^{\mathrm{a}, \mathrm{b}}\end{array}$ & $P$-value \\
\hline Height SDS & $-0.12(-0.17$ to -0.06$)$ & $<0.001$ \\
BMI SDS & $-0.21(-0.28$ to -0.14$)$ & $<0.001$ \\
Triceps skinfold SDS & $-0.19(-0.26$ to -0.13$)$ & $<0.001$ \\
Subscapular skinfold SDS & $-0.13(-0.18$ to -0.09$)$ & $<0.001$ \\
\hline
\end{tabular}

${ }^{\text {a }}$ Adjusted for age, sex and ethnic group.

${ }^{\mathrm{b}}$ Negative value indicates lower measurement in those receiving free meals. status or educational performance ${ }^{11}$. Effects of school meal provision on dietary intakes have been demonstrated $^{12}$, but studies in Britain since the $1980 \mathrm{~s}$ have generally shown that free meals or milk in school have a negligible effect on children's growth ${ }^{13,14}$. In Jamaica, however, receipt of meals in school was associated with greater increases in children's height and weight over a 12 -month period ${ }^{15}$. Provision of meals in school was also associated with better educational outcomes, including improved attendance at school ${ }^{15}$, and some evidence of better attention and cognitive functioning in class ${ }^{11,15,16}$. These nutritional and educational benefits were particularly important for poorly nourished children from lowincome families ${ }^{11,15}$.

Evidence for the differential effectiveness of school meals in children who are less well nourished provides support for a policy of targeting this provision to poorer families $^{15}$. However, when viewed as a social welfare measure, providing meals in schools acts as a transfer to 
families with children ${ }^{17}$. Here, the high degree of political acceptability of a benefit received directly by children may be as important as the immediate nutritional or educational consequences ${ }^{11}$. Targeting this form of provision has the apparent advantage of increasing the amount of benefit available to the poorest groups in society. A universal programme may be excessively costly. However, it is recognised that there are several disadvantages in targeting benefits in this way. Firstly, it may be difficult to implement a process of targeting efficiently, and it may be possible for the targeting to be subverted by the interests of particular groups ${ }^{18}$. Secondly, there may be a stigma associated with the receipt of targeted benefits, which may limit uptake among those who are eligible $e^{19,20}$. A policy of self-selection for school meals has been explored in some countries but this may increase inequity $^{21}$. In Jamaica a policy of self-selection led poorer children to choose the less costly meal, while children who had money to spend on food were able to choose the more costly cooked meal ${ }^{22}$. Thirdly, programmes that are aimed at the poor tend to attract few resources, or - as it is sometimes expressed 'programmes for the poor are poor programmes ${ }^{, 18}$.

In Trinidad and Tobago, the provision of free school meals was widespread but not universal. Although the basic policy is similar in the two islands, coverage tended to be more universal in Tobago (population approximately 50 000), but more selective in Trinidad (population approximately 1.2 million). There was some evidence of targeting at poorer children but, judged according to seven indicators of socio-economic status, this was incomplete and there were only small differences in anthropometric measures between those who received benefits and those who did not. There was also wide variation in the level of provision among schools, even after adjusting for the characteristics of children attending them.

Finally, it may be noted that at the present level of economic development there is little evidence of widespread undernutrition among children in Trinidad and Tobago. There is probably no excess of children with height less than -2 SDS but the prevalence of underweight is high especially in Indo-Trinidadian children ${ }^{3}$. In data from the survey reported here, $8.5 \%$ of children were overweight and $2.4 \%$ were obese ${ }^{3}$ according to the international standard for obesity in children ${ }^{23}$. Current global trends are towards increasing obesity. In this context, schools have a potential role in encouraging healthy eating and exercise habits ${ }^{24}$. School meals often have a high fat $\operatorname{content}^{25}$ but data reported to us by the School Nutrition Programme in Trinidad and Tobago suggest that their meals contain about $20 \%$ fat and $65-70 \%$ carbohydrate.

\section{Implications for policy}

The results of our survey raise questions about the objectives and implementation of the school feeding programme in Trinidad and Tobago. The original aim of the programme was to address undernutrition but a broader focus on promoting health may now be more appropriate. The current pattern of provision illustrates some of the documented tensions between differing policy objectives in school meals provision ${ }^{26}$. Greater equity could be achieved by making provision more universal as this would result in a higher proportion of children who need school meals actually receiving them. However, this would reduce efficiency, as more children who do not need free meals would then receive them. Greater efficiency would be achieved by making the criteria for accepting children for free school meals more stringent, and by reducing variation in provision between schools. The present pattern of provision may to some extent represent a pragmatic compromise between these conflicting objectives.

\section{Acknowledgements}

We thank the Chief Medical Officer of Trinidad and Tobago for permission to report this work. We also thank Dr Ramlal, PMO (CS), the staff of the Nutrition Division of the Ministry of Health, the Ministry of Education and the school supervisors, principals, teachers, parents and pupils at participating schools for their support and participation.

\section{References}

1 Sinha DP. Children of the Caribbean. Kingston, Jamaica: Caribbean Food and Nutrition Institute, PAHO/CFNI, 1988; 185.

2 Gulliford MC. Health and health care in the English-speaking Caribbean: a British public health physician's view of the Caribbean. J. Public Health Med. 1994; 16: 263-9.

3 Gulliford MC, Mahabir D, Rocke B, Chinn S, Rona RJ. Overweight, obesity and skinfold thicknesses of children of African or Indian descent in Trinidad and Tobago. Int. J. Epidemiol. 2001; 30: 989-98.

4 Cameron N. The methods of auxological anthropometry. In: Falkner F, Tanner JM, eds. Human Growth. A Comprehensive Treatise. Vol. 3. Methodology, Ecological, Genetic and Nutritional Effects on Growth. New York: Plenum Press, 1986; 3-46

5 Tanner JM, Whitehouse RH. Revised standards for triceps and subscapular skinfolds in British children. Arch. Dis. Child. 1975; 50: 142-5.

6 Republic of Trinidad and Tobago, Central Statistical Office. 1990 Population and Housing Census. Vol. 2. Age Structure, Religion, Ethnic Group, Education. Port of Spain: Office of the Prime Minister, Central Statistical Office, 1994.

7 Freeman JV, Cole TJ, Chinn S, Jones PR, White EM, Preece MA. Cross sectional stature and weight reference curves for the UK, 1990. Arch. Dis. Child. 1995; 73: 17-24.

8 Cole TJ, Freeman JV, Preece MA. Body mass index reference curves for the UK, 1990. Arch. Dis. Child. 1995; 73: 25-9.

9 Cole TJ. Fitting smoothed centile curves to reference data (with discussion). J. Roy. Statist. Soc. A 1988; 151: 385-418.

10 Stata Corporation. Stata Reference Manual. Release 7. Vol. 4 Su-Z. College Station, TX: Stata Corporation, 2001.

11 Grantham-McGregor SM, Chang S, Walker SP. Evaluation of school feeding programs: some Jamaican examples. $\mathrm{Am}$. J. Clin. Nutr. 1998; 67: 785S-9S. 
12 Gordon AR, Devaney BL, Burghardt JA. Dietary effects of the National School Lunch Program and the School Breakfast Program. Am. J. Clin. Nutr. 1995; 61: 221S-31S.

13 Baker IA, Elwood PC, Hughes J, Jones M, Moore F, Sweetnam PM. A randomised controlled trial of the effect of the provision of free school milk on the growth of children. J. Epidemiol. Community Health 1980; 34: 31-4.

14 Rona RJ, Chinn S. School meals, school milk and height of primary school children in England and Scotland in the eighties. J. Epidemiol. Community Health 1989; 43: 66-71.

15 Powell CA, Walker SP, Chang SM, Grantham-McGregor SM Nutrition and education: a randomized trial of the effects of breakfast in rural primary school children. Am.J. Clin. Nutr. 1998; 68: 873-9.

16 Chandler AM, Walker SP, Connolly K, Grantham-McGregor SM. School breakfast improves verbal fluency in undernourished Jamaican children. J. Nutr. 1995; 125: 894-900.

17 Maurer KM. The National Evaluation of School Nutrition Programs: program impact on family food expenditures. Am. J. Clin. Nutr. 1984; 40: 448-53.

18 Gelbach JB, Lant HP. More for the Poor is Less for the Poor: Politics of Targeting. Working Paper 1799. New York: World Bank, 2001.

19 Rona RJ, Chinn S. Parents' attitudes towards school meals for primary school children in 1981. Hum. Nutr. Appl. Nutr. 1984; 38: 187-98.

20 Glovinsky-Fahsholtz D. The effect of free or reduced-price lunches on the self-esteem of middle school students. Adolescence 1992; 27: 633-8.

21 Jacoby HG. Self-selection and the redistributive impact of inkind transfers - an econometric analysis. J. Hum. Resourc. 1997; 32: 233-49.

22 Walker SP, Powell CA, Hutchinson SE, Chang SM, GranthamMcGregor SM. School children's diets and participation in school feeding programmes in Jamaica. Public Health Nutr. 1998; 1: 43-9.

23 Cole TJ, Bellizzi MC, Flegal KM, Dietz WH. Establishing a standard definition for child overweight and obesity worldwide: international survey. Br. Med.J. 2000; 320: 1-6.

24 Wechsler H, Devereaux RS, Davis M, Collins J. Using the school environment to promote physical activity and healthy eating. Prev. Med. 2000; 31: S121-37.

25 Pannell DV. Why school meals are high in fat and some suggested solutions. Am. J. Clin. Nutr. 1995; 61: 245S-6S.

26 Rose R, Falconer P. Individual taste or collective decision public policy on school meals. J. Social Policy 1992; 21 : $349-73$. 